\title{
Drivers of Change in Estuarine and Coastal Marine Environments: An Overview
}

\author{
Michael J. Kennish \\ Department of Marine and Coastal Sciences, Rutgers University, New Brunswick, NJ, USA \\ Email:kennish@marine.rutgers.edu
}

How to cite this paper: Kennish, M.J. (2021) Drivers of Change in Estuarine and Coastal Marine Environments: An Overview. Open Journal of Ecology, 11, 224-239. https://doi.org/10.4236/oje.2021.113017

Received: January 25, 2021

Accepted: February 23, 2021

Published: February 26, 2021

Copyright $\odot 2021$ by author(s) and Scientific Research Publishing Inc. This work is licensed under the Creative Commons Attribution International License (CC BY 4.0).

http://creativecommons.org/licenses/by/4.0/

\begin{abstract}
Anthropogenic climate and non-climate drivers of change are causing significant impacts on estuarine and coastal marine environments. Climate change poses a particular threat to the structure and function of biotic communities in these environments because it acts on the most extensive temporal and spatial scales relative to other anthropogenic drivers of change. The interaction of multiple environmental drivers exacerbates degradation of ecosystem condition. Estuaries are most susceptible to climate-change mediated biotic shifts and direct anthropogenic impacts due to burgeoning human population growth and development in coastal watersheds. Multiple anthropogenic drivers of change, which often interact synergistically, alter physical, chemical, and biological characteristics. Ecological responses may be increasingly nonlinear, with cumulative effects manifested by marked changes in organism abundance, distribution, diversity, and productivity. Detrimental biotic effects in impacted coastal environments cascade up from individual organisms to population and community levels, culminating in ecosystem-level changes including reduced services. Multiple drivers of change and their impacts are increasing in estuarine and coastal marine environments with greater anthropogenic forcing in the coastal zone and global effects of climate change, creating greater challenges for environmental management and conservation programs.
\end{abstract}

\section{Keywords}

Multiple Drivers, Climate Change, Anthropogenic Impacts, Estuaries, Coastal Marine Environments, Management, Conservation, Resilience

\section{Introduction}

Anthropogenic climate and non-climate drivers of change pose an increasing threat to sustainability of estuarine and coastal marine environments and their 
ecological and economic services. Multiple drivers of change coupled to human activities cause a flux in abiotic conditions and a shift in biotic responses, resulting in significant impacts on these environments. For example, increasing water temperature, deoxygenation, altered precipitation and freshwater inputs, variable salinity, rising sea levels, modified circulation, acidification, nutrient enrichment, chemical contaminants, fishing pressure, and invasive species lead to marked changes in estuarine biotic communities and habitats [1] [2]. Environmental drivers vary significantly in space and time, influencing physiological responses of organisms, their behavior, and trophic interactions, often culminating in altered demographic characteristics, community structure, and ecosystem function [3].

Warming of estuarine and coastal marine waters, including marine heatwaves driven by climate change, is altering species abundance, distribution, diversity, community composition, and habitat sustainability [3] [4] [5] [6] [7]. Rising water temperatures increase water column stratification, alter nutrient dynamics and biotic productivity, and modulate other vital biotic processes. Changing climate regimes are shifting estuarine and marine species distributions through species specific physiological thresholds of temperature and precipitation tolerance [3] [8] [9]. Climate-mediated changes in seasonal phenology of organisms directly alter estuarine and marine community composition [3]. Pinsky et al. [10] project greater rates of population-level extirpation in marine waters due to warming climate, which will have cascading effects on trophic dynamics during the $21^{\text {st }}$ century. In addition, the loss of essential coastal habitat (e.g., salt marshes, mangroves, and seagrasses) due to temperatures exceeding critical species threshold levels and rising sea levels inundating low-lying wetlands will not only eliminate extensive habitat for numerous estuarine and marine organisms but also decrease the habitat capacity for carbon sequestration and greenhouse gas mitigation.

Estuaries are particularly susceptible to climate-change mediated shifts and multiple environmental drivers coupled to direct anthropogenic activities [1] [2] [8]. This is so because climate change effects are often amplified in coastal areas, and human population growth, development, and activities are disproportionately increasing in estuarine watersheds which are heavily used for their services [2] [11] [12]. In addition, estuaries are highly variable environments where the flux of numerous factors causes quantifiable ecological change. The list of local, regional, and global drivers of change is extensive, and their combined effects on physical-chemical processes, biotic communities, and ecosystem function of estuaries can be transformative [1] [7] [13] [14].

The objective of this work is to examine drivers of change in estuarine and coastal marine environments, their sources, interactions, and effects. Global climate change and direct anthropogenic impacts are altering the basic properties, physical and chemical characteristics, and ecological processes of these environments. These effects are occurring at an accelerated rate with increasing climate change and direct anthropogenic impacts in the coastal zone, which are 
modulating ecological responses in affected ecosystems.

\section{Drivers of Coastal Ecosystem Change}

Estuarine and coastal marine ecosystems are more susceptible to the interaction of multiple climate and non-climate anthropogenic drivers of change than are open ocean ecosystems. The conversion of natural land covers to agricultural, urban, and industrial development has accelerated pollution loading in rivers discharging to estuaries and coastal marine waters, resulting in cascading water quality and biotic impacts, habitat impairments, and diminishing recreational and commercial use. Storm surges and wind forcing, construction of dams, dikes, and artificial bars, as well as channel dredging and freshwater diversions for farm irrigation and other human needs, are important drivers of hydrological change, accounting for fluxes in sediment, nutrient, and other constituent inputs to estuaries and coastal marine waters. Shallow coastal lagoons and coastal bays with restricted circulation, low freshwater inflow, limited flushing rates, and relatively long residence times, are sinks for nutrient enrichment and other substances from surface runoff, groundwater, and atmospheric inputs. Thus, they are sites of potentially greater anthropogenic impacts.

Climate change drivers, including higher intensity storms, increasing water temperatures, rising sea levels, extreme floods, and droughts interact with direct anthropogenic drivers of change to exacerbate overall impacts in estuarine and coastal marine environments. High precipitation and runoff from hurricanes and coastal storms result in freshwater pulses that significantly alter hydrologic and biogeochemical processes, albeit ephemerally, and changing physicochemical characteristics of affected estuarine and shallow coastal marine waters can cause marked shifts in salinity structure and flushing times, nutrient concentrations, total suspended solids, and other constituents [15]. Combined effects of multiple drivers and internal filters typically culminate in nonlinear recovery trajectories, with the structure and function of estuarine and coastal marine waters being altered [16] [17]. For example, impacts of eutrophication can be numerous and varied and, depending on physicochemical and biotic conditions, may include the occurrence of hypoxia/anoxia, harmful algal blooms (HABs), biogeochemical alteration, loss of essential habitat (e.g., seagrass and shellfish beds), reduced biodiversity, declining harvestable fisheries, imbalanced trophic food webs, decreasing system resilience, diminished ecosystem services, and impacted human use [18] [19] [20] [21] [22].

The list of anthropogenic drivers of change in estuarine and coastal marine environments is extensive and can be organized into 12 major categories, including: 1) habitat loss and alteration (e.g., lagoon construction, shoreline hardening, and land reclamation); 2) enrichment (e.g., nutrients, organic carbon, and thermal loading); 3) sewage and pathogenic inputs; 4) chemical contaminants; 5) human-induced sediment/particulate inputs; 6) dredging and dredged-material disposal; 7) human-altered hydrological regimes; 8) invasive/introduced species; 
9) overfishing and intensive aquaculture; 10) coastal subsidence; 11) floatables/plastics/debris; and 12) climate change effects. These factors can significantly affect the ecological integrity, sustainability, and ecosystem services of these environments. Anthropogenic drivers of change can be divided into physical, chemical, and biotic factors. They also can be categorized by whether they compromise water quality, alter biotic communities, degrade habitat, or are driven by climate change (Table 1). Drivers that impact water quality include (chemical) pollution due to nutrient enrichment, organic carbon loading, and chemical contaminants. Drivers that alter biotic communities include pathogens, overfishing, and introduced/invasive species. Physical drivers degrade habitats and include dredging and ditching, shoreline structural modification, and wetlands reclamation; however, chemical pollution can also decimate essential habitat such as seagrass beds [21] [23].

Table 1. Major anthropogenic drivers of change in estuarine and coastal marine environments.

Drivers

Class 1 (Degrade Water Quality)

Nutrient Enrichment/Eutrophication

Organic Carbon and Thermal Loading

Biogeochemical Alteration

Chemical Contaminants

Sewage Inputs

Pathogens

Class 2 (Impact Habitat)

Watershed Development

Watershed Impervious Cover

Sediment/Particulate Inputs

Dredging and Dredged-Material Disposal

Shoreline Hardening

Erosion

Lagoon Construction

Land Reclamation

Coastal Subsidence

Class 3 (Alter Biotic Communities)

Human-altered Hydrological Regimes

Overfishing

Intensive Aquaculture

Invasive/Introduced Species

Floatables/Plastics/Debris

Class 4 (Climate Linked)

Climate Change Drivers

$\mathrm{CO}_{2}, \mathrm{CH}_{4}, \mathrm{NO}_{2}$, Chlorofluorocarbons, (Greenhouse Gases)

Warming Temperatures

Precipitation and Land Runoff

Extreme Events

Hurricanes and Other Major Storms

Storm Surges

Tornadoes

Droughts 
Anthropogenic climate change acts on the most extensive temporal and spatial scales relative to other anthropogenic drivers of change [3] [4] [11] [24]. Effects of climate change drivers in estuarine and coastal marine waters cascade up from individual organisms to population and community levels, culminating in ecosystem-level changes (e.g., species diversity and distribution, ecosystem productivity, and ecosystem services). While the ecosystem responses to climate change drivers are often unpredictable, impacts on both abiotic and biotic variables can shift an estuary or coastal marine embayment beyond critical thresholds leading to the degradation and loss of ecosystem function and services [4] [24]. The capacity for recovery of an impacted estuary or coastal embayment from climate change drivers is increased by connectivity among species, populations and ecosystems [24].

\section{Multiple Driver Interactions}

Some investigators have used the term "stressor" synonymously with "driver," while others perceive fundamental differences in these descriptors. For example, Côté et al. [25] defined a stressor as akin to a driver in that it represents a natural or anthropogenic pressure causing a quantifiable positive or negative change in biotic response. In contrast, Folt et al. [26] described a stressor as "any environmental factor that reduces population growth via a reduction in survivorship or reproduction relative to optimum conditions." They stated that the effect of a stressor is exclusively negative. Similarly, Boyd and Hutchins [14] defined a stressor as a negative factor of environmental change that decreases organismal fitness, while defining a driver as a positive or negative factor of environmental change that results in a quantifiable biological response, ranging from stress to enhancement. Thus, Boyd et al. [7] considered the term "driver" to be a more accurate descriptor than "stressor" when assessing and predicting ecological change.

Environmental and anthropogenic drivers typically act together rather than in isolation, and their effects are usually more acute in combination than in isolation [26] [27]. Estuarine and coastal marine organisms, therefore, are often exposed to two or more drivers concurrently, and their interactions can greatly influence populations and communities, as well as ecosystem function and services. Multiple driver effects in these organisms can be additive, synergistic, or antagonistic. When the ecological effect of one driver depends on the magnitude of another, the combined effect can be greater or less than expected (i.e., synergistic or antagonistic), rather than additive or multiplicative [28] [29]. When the combined effect of multiple drivers exceeds the expected additive effect of individual drivers, the interactive effect is synergistic. When the combined effect of multiple drivers is less than the expected additive effect of the individual drivers, the interactive effect is antagonistic. When the combined effect of multiple drivers equals the sum of the effects of each driver, the interactive effect is additive [7] [25] [27] [28] [29] [30] [31]. 
Studies of single drivers of change have employed a traditional reductive approach in which one environmental property of estuarine or marine waters (e.g., temperature, dissolved oxygen, or $\mathrm{pH}$ ) is altered experimentally to assess biotic and ecosystem responses [32]. In estuarine and marine environments, however, multiple interactive drivers associated with anthropogenic climate change and non-climate pressures account for significant nonlinear effects of cumulative environmental impacts on biotic communities and ecosystem function [24] [27] [28] [33] [34] [35]. In addition, biotic communities in these environments respond via a range of mechanisms to climate drivers (e.g., temperature, deoxygenation, and $\mathrm{CO}_{2}$ ) that combine with direct anthropogenic drivers (e.g., nutrient enrichment, chemical contaminants, sedimentation, invasive species, and overfishing) to create instability [36] [37]. These drivers may act in any combination, with the cumulative impacts contingent upon the strength of the individual drivers. Responses of organisms will also depend on interactions with assemblages or communities of other organisms in an area. Because of the large number of possible driver combinations, species community combinations, environmental conditions, and cost of study, experimental work investigating driver impacts in a wide range of situations is limited [27].

Synergisms between anthropogenic climate and non-climate drivers are of particular concern because they can exacerbate climate-induced changes alone. They are a special case of non-independent effects that may occur by the following: 1) the impact of one factor either strengthened or weakened by variation in another; and 2) the combined influence of two drivers that pushes an organism or population beyond a critical threshold that would not be reached via variation in either driver acting alone [35]. Predicting ecological change due to synergistic as well as antagonistic interactions between multiple drivers is exceedingly difficult in highly variable estuarine and coastal marine environments. Under changing climatic conditions, the cumulative effects of multiple drivers on ecological responses (e.g., species abundance, diversity, productivity, and mortality) are amplified by variable synergistic and antagonistic interactions that can be detrimental to estuarine and marine organisms [3] [25] [28].

In a comprehensive investigation of 14 anthropogenic drivers in 21 marine ecosystems (e.g., seagrasses, mangroves, kelp forests, and coral reefs) over an 11-year period, Halpern et al. [35] concluded that multiple drivers-notably climate change as well as land-based pollution, fishing, and other non-climate anthropogenic pressures-are causing significantly increasing cumulative impacts on more than half (59\%) of the global oceans. Halpern et al. [34] applied an Ocean Health Index to evaluate potential drivers and consequences of changes in marine ecosystems, as well as to track progress towards achieving policy and societal goals for improving ocean health. They ascribed anthropogenic climate change as the main driver of increased human impact on these ecosystems (see also Halpern et al. [12]).

The drivers of change that occur in estuarine and coastal marine environments are too numerous for investigators to measure all potential interactions 
between every combination of drivers. Hence, identifying generalities about ecosystems, drivers, and responses may be a more realistic goal for predicting interaction types [25]. Griffen et al. [27] advocate the application of a general framework based on mechanistic understanding of multiple stressor impacts in marine ecosystems. There are three steps comprising this framework: 1) mechanistically examining the impacts of multiple stressors on individual organisms; 2) scaling these impacts on individual organisms to population level responses to multiple stressors; and 3) investigating context-dependent changes in stressor responses due to changes in community or ecosystem properties.

Identifying driver interactions and predicting their ecological outcomes would greatly inform conservation programs in estuarine and coastal marine environments, but they are increasingly difficult tasks, especially predicting ecological outcomes, hindered by the combined impacts of multiple drivers that can vary considerably with the type of factors involved. In addition, different species of organisms often do not respond similarly to the same environmental and anthropogenic drivers [27]. Moreover, the ecological effect of one driver frequently depends on the magnitude of another. Thus, a common metric would be useful for integrating the impacts of multiple drivers. Currently, the ability to forecast outcomes at higher levels of organization is very limited [29]. To inform management and conservation programs, it is necessary to increase the capacity to predict the combined impacts of multiple drivers under an array of environmental conditions [27]. One objective is to implement management actions that are robust to uncertainty in interaction types and can build resilience to intensifying drivers of change [25].

Some investigations have attempted to make inferences from single driver studies of responses in multivariate environments, but this approach seldom provides reliable predictions about responses [7]. Measuring the effects of multiple interactive environmental drivers in highly variable estuarine and coastal marine waters remains a challenging problem in part because of confounding factors. However, more investigations are being conducted on multiple driver interactions that are increasing understanding of anthropogenic climate and non-climate effects. Data are being compiled on the frequency and intensity of the drivers as well as their spatial and temporal patterns of occurrence, not only to document multiple driver impacts but also to predict the combined impacts of these drivers under variable conditions [7] [27] [34] [38].

\section{Environmental Complexity}

The degree of environmental complexity influences multiple environmental driver impacts on organisms in estuarine and marine environments. The intensity of cumulative stresses can differ significantly in estuarine, coastal ocean, and open ocean waters due to environmental heterogeneity [14]. Local anthropogenic impacts and habitat heterogeneity dominate in estuaries and other coastal waters where human activities are greatest and land-derived pollutants peak. In these ecosystems, environmental heterogeneity varies spatially and temporally 
with the flux in physical and chemical variables and alteration of water quality and habitats due to human activities [1] [2] [13]. Intrinsic differences in environmental heterogeneity confound intercomparison of biological responses to multiple drivers across systems [14].

The open ocean is less impacted by direct human activities than are coastal environments. Estuaries in particular are spatially limited, often surrounded by highly populated land areas, and commonly impacted by physical alteration of habitats and allochthonous inputs of pollutants from land runoff. Open ocean waters have much greater expanse than estuaries and are distant from many direct human activities. Therefore, global and regional anthropogenic drivers predominate in the open ocean, such as $\mathrm{CO}_{2}, \mathrm{pH}$, temperature, and atmospheric pollutants [14].

Boyd and Hutchins [14] discussed interactive global change factors that elicit responses of biotic communities in open ocean waters. Studies have demonstrated the importance of interactive environmental controls on the base of pelagic food webs. For example, the growth and productivity of Antarctic phytoplankton communities are synergistically amplified by the concurrent warming and iron-enrichment of ocean waters [39]. Growth of coccolithophores in the North Atlantic also increases with concurrent warming and rising $\mathrm{CO}_{2}$ concentrations [40]. Experimental investigations are needed on interactive environmental controls affecting higher trophic levels in the open ocean. Little is known about the nonlinear effects of cumulative regional and global environmental stresses on faunal communities in the ocean.

Climate change is an escalating problem affecting the physical, chemical, and biological characteristics of estuarine and marine environments. Warming waters, sea level rise, acidification, higher intensity storms, and other drivers of change can significantly alter biotic communities and habitats in these environments [2] [6] [13] [33]. Degradation and loss of habitats due to climate change notably modulate environmental heterogeneity, influencing ecosystem structure and function [7] [14].

\section{Experimental Studies}

Many studies have focused on experimental laboratory testing of organisms to assess effects of interactive drivers. Crain et al. [30] summarized additive, synergistic, and antagonistic impacts of multiple stressors in marine and coastal ecosystems, synthesizing 171 multiple stressor studies in the literature to assess cumulative stressor effects. They found that cumulative effects of any two stressors were distributed among all interaction types, with $26 \%$ additive, $36 \%$ synergistic, and $38 \%$ antagonistic. However, the overall interaction across all studies was synergistic, indicating that multiple stressor cumulative effects are often worse than expected based on single stressor impacts. In contrast, Piggott et al. [31] reported that antagonistic impacts of multiple stressors are generally more common than synergistic impacts. Although it is difficult to determine multiple stressor effects in estuarine and coastal marine environments considering the 
complex interactive natural and anthropogenic drivers of change occurring there, these data are important for informing management and conservation programs to improve environmental conditions.

The multifarious nature of environmental change due to shifting anthropogenic climate and non-climate factors confound predictions of multiple driver interactions and biotic responses to them as noted above. Laboratory experimental designs are advancing from manipulation of a single environmental factor to designs that manipulate two or more environmental factors. Gunderson et al. [28] reviewed three multiple stressor experimental design components involving marine organisms: 1 ) those subjecting a set of organisms to baseline levels of all stressors; 2) those subjecting additional sets of organisms to elevated levels of each stressor individually; and 3) those subjecting another set of organisms to elevated levels of all stressors. Multiple factor experimental designs yield more realistic inferences about interactive anthropogenic climate and non-climate driver impacts in estuarine and coastal marine environments.

Boyd et al. [7] identified five main approaches used to understand the effect of environmental drivers on marine biota: 1) paleo-proxies; 2) modern proxies; 3) modern observations; 4) manipulative microcosm experiments; and 5) large-volume mesocosm experiment enclosures. Experimental approaches that have been applied range from single species, small-scale experiments to mesocosm studies and larger, open natural experiments. Taken together, these approaches improve the research base for predicting and managing the interactive effects of multiple drivers on estuarine and marine organisms and ecosystems. As experimental databases increase, more information is assembled with assessments leading to more accurate interpretations of complex multiple driver interactions.

Of the 171 experiments included in the analysis of multiple stressors in marine ecosystems by Crain et al. [30], 73\% were conducted in the laboratory, $17 \%$ in mesocosms, and $10 \%$ in the field. Results of their analysis showed that the laboratory experiments were predominantly synergistic, while the mesocosm studies were significantly antagonistic and the field studies additive. The authors noted that these results may be due to researchers targeting potentially negative interaction studies in the laboratory, mainly community-level studies in mesocosms, while balancing complex interactions in the field. Another explanation for the differences in overall interaction type is that they may be a byproduct of the stressor pairs studied using different methodologies, although stressor pair bias is unlikely because of the large diversity of stressor pairs used in the analysis. When interactions are expected, researchers often conduct factorial experimentation. Although some stressors (e.g., chemical toxins) are effectively addressed via factorial experimentation, other stressors (e.g., invasive species and overfishing) are much less amenable to it.

The work of Gunderson et al. [28] supported the findings of Crain et al. [30]. They conveyed that the most common interactive effect recorded in multiple stressor studies appears to be synergism, suggesting that exposure of marine organisms to multiple stressors under climate change conditions will result in de- 
trimental effects. Many multiple stressor experimental studies of climate change effects on estuarine and marine organisms have targeted the combined effects of temperature and/or $\mathrm{pH}$ with other stressors. Often a pair of stressors is examined, rather than single stressors. Estuarine and marine organisms in nature are affected by multiple stressors that vary temporally, spatially, and in intensity. However, experimental multiple stressor studies commonly expose organisms to stressors simultaneously and at constant intensity levels, which deviate from natural conditions. Thus, researchers must be careful when comparing the results of the experimental studies in the laboratory to effects observed in nature, particularly employing single stressor studies.

There are many potential stressor combinations affecting estuarine and marine organisms because of the dynamic and multifactorial nature of coastal habitats and the wide array of anthropogenic influences, particularly in estuaries and coastal lagoons. A mechanistic approach in experimental studies typically uses a gradient of treatments to determine the organismal response to a selected range of environmental conditions. The manipulative experiments provide mechanistic insights into how multiple drivers affect biota. With escalating climate change effects in estuarine and marine environments over the past two decades, Boyd et al. [7] convey that a scenario-based approach has gained favor in experimental studies to assess responses of marine organisms to individual drivers and combinations of drivers (see also Yang et al. [41]). According to Boyd et al. [7], this approach differs from a mechanistic approach mainly by the rationale for the choice and levels of drivers used in experiments to predict biotic responses to environmental change. A major goal is to improve prediction and greater understanding of multiple stressor effects and when they will combine additively, synergistically, or antagonistically [27].

With increasing effects of climate change and direct anthropogenic activities in the coastal zone, multiple driver interactions are on the rise, leading to greater uncertainties in predicting ecological impacts on organisms and ecosystems and challenging coastal management programs [42]. Pigott et al. [31] recommend that researchers simplify the condition by using experimental treatments that reflect natural combinations of stressors and not designs that separate the effects of individual stressors, yielding less manageable databases. This change in focus promotes practical applications that will improve conservation management programs to remediate ecological impacts. As stated by Pigott et al. [31], "Aggregating stressors reduce the number of factorial combinations required to quantify the benefits of managing stressors involved in multiple interactions." However, by aggregating stressors, the effects of individual stressors cannot be isolated, thereby limiting data acquisition on organismal responses to some stressor interactions.

\section{Management Implications}

Estuarine and coastal marine environments are managed to minimize biotic community and ecosystem impacts due to multiple driver effects linked to 
anthropogenic climate and non-climate factors. Reducing uncertainty of driver interactions and improving the prediction and outcome of the interactions is vital for conservation management programs to strengthen ecosystem resilience. Once greater resolution of driver interactions is achieved, restoration and other remedial management measures should follow. Effective policies will bolster the interventions and other resilience-based approaches necessary to mitigate multiple driver impacts [24].

Resilience has been defined as the capacity of a system to maintain function, structure, and feedbacks in the face of disturbance [43]. There are three components of resilience in estuarine and coastal marine ecosystems: 1) resistance to change of structure and function; 2) capacity for recovery and self-organization; and 3) capacity to adapt to new conditions (e.g., higher temperatures, lower $\mathrm{pH}$, and deoxygenation) [44]. However, greater interaction of anthropogenic climate and non-climate drivers reduces ecological resilience and can cause the loss of ecosystem services, such as fisheries resources, protective habitat, and recreational usage.

Managing for resilience is a way to sustain valuable ecosystem services of estuarine and coastal marine environments. An important step is to monitor and assess ecosystem conditions that can track resilience components (i.e., diversity, connectivity, and adaptive capacity). Understanding the dynamic nature of ecosystem function is an important part of ecosystem-based approaches to estuarine and marine management and conservation. To ensure persistence of coastal marine ecosystems in the face of multiple drivers of change, the ecological mechanisms that enable ecosystems to resist, adapt, and recover from climate flux and other anthropogenic impacts must be protected [24]. These components should be investigated empirically if a resilience framework is to successfully influence resource management.

Successful ecosystem-based management programs are place-based efforts, which often include climate adaptation and protection strategies, such as establishing marine protected areas (MPAs), installing living shorelines, and restoring impacted habitats (e.g., altered coastal wetlands) [45]. The implementation of MPAs increases diversity, connectivity, and adaptive capacity, which promote resilience [44]. Connectivity and adaptive capacity in particular are system properties contributing to population and ecosystem resilience. Assessing population sizes, species diversity, genetic diversity, and other monitoring proxies of ecological resilience is important for determining the efficacy of adaptive management programs [24]. The ultimate goal is to mitigate anthropogenic climate and non-climate drivers that interact to diminish resilience and ecosystem function of estuarine and coastal marine environments.

\section{Conclusions}

1) Disproportionate increases in human population growth and development in coastal watersheds have adversely affected the structure and function of many estuarine and coastal marine ecosystems. 
2) The interaction of anthropogenic climate and non-climate drivers is causing significant impact on coastal environments.

3) There are many driver combinations affecting these environments because of the dynamic and multifactorial nature of habitats and the wide array of anthropogenic impacts.

4) A driver is defined as a positive or negative factor of environmental change that results in a quantifiable biological response, ranging from stress to enhancement [14].

5) Interactive multiple driver effects may be additive, synergistic, or antagonistic. The nonlinear effects of cumulative stresses can compromise organismal fitness and biotic community structure.

6) Multiple drivers often interact synergistically, with their combined impacts being greater than the sum of their individual impacts. Synergistic interaction of multiple drivers can be especially damaging to coastal ecosystems.

7) Effects of climate drivers in estuarine and coastal marine environments cascade up from individual organisms to population and community levels, culminating in ecosystem-level changes (e.g., species diversity and distributions, ecosystem productivity, and ecosystem services).

8) Climate drivers altering abiotic and biotic variables can shift an estuary beyond critical thresholds leading to the degradation and loss of ecosystem function and services.

9) Climate change poses a particular threat to the functioning of estuaries and other coastal ecosystems because it acts on the most extensive temporal and spatial scales relative to other anthropogenic drivers of change.

10) Identifying multiple driver interactions and predicting their ecological outcomes is a major challenge for coastal management and conservation programs.

11) More effective analysis and modeling of biotic community and ecosystem responses to multiple driver interactions will facilitate conservation planning and resilience building of estuarine and coastal marine environments.

12) Managing for resilience is a way to sustain valuable ecosystem services of these important environments.

\section{Acknowledgements}

This is Contribution Number 6146 of the Department of Marine and Coastal Sciences, Rutgers University, New Brunswick, New Jersey (USA).

\section{Conflicts of Interest}

The author declares no conflicts of interest regarding the publication of this paper.

\section{References}

[1] Kennish, M.J. (2002) Environmental Threats and Environmental Future of Estuaries. Environmental Conservation, 29, 78-107. 
https://doi.org/10.1017/S0376892902000061

[2] Kennish, M.J. (2016) Encyclopedia of Estuaries. Springer, Dordrecht. https://doi.org/10.1007/978-94-017-8801-4

[3] Doney, S.C., Ruckelshaus, M., Duffy, J.E., Barry, J.P., Chang, F., English, C.A., et al. (2012) Climate Change Impacts on Marine Ecosystems. Annual Review of Marine Science, 4, 11-37. https://doi.org/10.1146/annurev-marine-041911-111611

[4] Hoegh-Guldberg, O. and Bruno, J.F. (2010) The Impact of Climate Change on the World's Marine Ecosystems. Science, 328, 1523-1528.

https://doi.org/10.1126/science.1189930

[5] Poloczanska, E.S., Brown, C.J., Sydeman, W.J., Kiessling, W., Schoeman, D.S., Moore, P.J., et al. (2013) Global Imprint of Climate Change on Marine Life. Nature Climate Change, 3, 919-925. https://doi.org/10.1038/nclimate1958

[6] Poloczanska, E.S., Burrows, M.T., Brown, C.J., Molinos, J.G., Halpern, B.S., Hoegh-Guldberg, O., et al. (2016) Responses of Marine Organisms to Climate Change across Oceans, Frontiers in Marine Science, 3, 62.

https://doi.org/10.3389/fmars.2016.00062

[7] Boyd, P.W., Collins, S., Dupont, S., Fabricius, K., Gattuso, J-P., Havenhand, J., et al. (2018) Experimental Strategies to Assess the Biological Ramifications of Multiple Drivers of Global Ocean Change. Global Change Biology, 24, 2239-2261.

https://doi.org/10.1111/gcb.14102

[8] Robins, P.E., Skov, M.W., Lewis, M.J., Giménez, L., Davies, A.G., Malham, S.K., et al. (2016) Impact of Climate Change on UK Estuaries: A Review of Past Trends and Potential Projections. Estuarine, Coastal and Shelf Science, 169, 119-135. https://doi.org/10.1016/j.ecss.2015.12.016

[9] Collins, M., Sutherland, M., Bouwer, L., Cheong, S-M., Frölicher, T., Jacot Des Combes, H., et al. (2019) Extremes, Abrupt Changes and Managing Risks. In: Pörtner, H.-O., Roberts, D.C., Masson-Delmotte, V., Zhai, P., Tignor, M., Poloczanska, E.S., et al., Eds., IPCC Special Report on the Ocean and Cryosphere in a Changing Climate, Chapter 6, Intergovernmental Panel on Climate Change, Geneva, 589-655.

[10] Pinsky, M.L., Eikeset, A.M., McCauley, D.J., Payne, J.L. and Sunday, J.M. (2019) Greater Vulnerability to Warming of Marine Versus Terrestrial Ectotherms. Nature, 569, 108-111. https://doi.org/10.1038/s41586-019-1132-4

[11] Halpern, B.S., Walbridge, S., Selkoe, K.A., Kappel, C.V., Micheli, F. and D’Agrosa, C. (2008) A Global Map of Human Impact on Marine Ecosystems. Science, 319, 948-952. https://doi.org/10.1126/science.1149345

[12] Halpern, B.S., Frazier, M., Potapenko, J., Casey, K.S., Koenig, K., Longo, C., et al. (2015) Spatial and Temporal Changes in Cumulative Human Impacts on the World's Ocean. Nature Communications, 6, Article No. 7615. https://doi.org/10.1038/ncomms8615

[13] Kennish, M.J. (2019) Practical Handbook of Marine Science. 4th Edition, CRC Press, Boca Raton. https://doi.org/10.1201/b22246

[14] Boyd, P.W. and Hutchins, D.A. (2012) Understanding the Responses of Ocean Biota to a Complex Matrix of Cumulative Anthropogenic Change. Marine Ecology Progress Series, 470, 125-135. https://doi.org/10.3354/meps10121

[15] Paerl, H.W., Crosswell, J.R., Van Dam, B., Hall, N.S., Rossignol, K.L., Osburn, C.L., et al. (2018) Two Decades of Tropical Cyclone Impacts on North Carolina's Estuarine Carbon, Nutrient, and Phytoplankton Dynamics: Implications for Biogeochemical Cycling and Water Quality in a Stormier World. Biogeochemistry, 141, 
307-332. https://doi.org/10.1007/s10533-018-0438-x

[16] Viaroli, P., Bartoli, M., Giordani, G., Naldi, M., Orfavidis, S. and Zaldivar, J.M. (2008) Community Shifts, Alternate Stable States, Biogeochemical Controls and Feedbacks in Eutrophic Coastal Lagoons: A Brief Overview. Aquatic Conservation: Marine and Freshwater Ecosystems, 18, S105-S117. https://doi.org/10.1002/aqc.956

[17] Duarte, C.M., Conley, D.J., Carstensen, J. and Sánchez-Camacho, M. (2009) Return to Neverland: Shifting Baselines Affect Eutrophication Restoration Targets. Estuaries and Coasts, 32, 29-36. https://doi.org/10.1007/s12237-008-9111-2

[18] Paerl, H.W., Valdes, L.M.L., Peierls, B.L., Adolf, I.A. and Harding Jr., L.W. (2006) Anthropogenic and Climatic Influences on the Eutrophication of Large Estuarine Ecosystems. Limnology and Oceanography, 51, 448-462.

https://doi.org/10.4319/lo.2006.51.1_part_2.0448

[19] Kennish, M.J., Bricker, S.B., Dennison, W.C., Glibert, P.M., Livingston, R.J., Moore, K.A., et al. (2007) Barnegat Bay-Little Egg Harbor Estuary: Case Study of a Highly Eutrophic Coastal Bay System. Ecological Applications, 17, S3-S16. https://doi.org/10.1890/05-0800.1

[20] Kennish, M.J. (2009) Eutrophication of Mid-Atlantic Coastal Bays. Bulletin of the New Jersey Academy of Science, 54, 5-12.

[21] Kennish, M.J. and de Jonge, V.N. (2011) Chemical Introductions to the Systems: Diffuse and Nonpoint Source Pollution from Chemicals (Nutrients: Eutrophication). In: Kennish, M.J. and Elliott, M., Eds., Treatise on Estuarine and Coastal Science, Vol. 8, Elsevier, Oxford, 113-148.

https://doi.org/10.1016/B978-0-12-374711-2.00806-8

[22] Howarth, R.W., Chan, F., Conley, D.J., Garnier, J., Doney, S.C., Marino, R. and Billen, G. (2011) Coupling Biogeochemical Cycles: Eutrophication and Hypoxia in Temperate Estuaries and Coastal Marine Ecosystems. Frontiers in Ecology and the Environment, 9, 18-26. https://doi.org/10.1890/100008

[23] Kennish, M.J. and Paerl, H.W. (2010) Coastal Lagoons: Critical Habitats of Environmental Change. CRC Press, Boca Raton. https://doi.org/10.1201/EBK1420088304

[24] Bernhardt, J.R. and Leslie, H.M. (2013) Resilience to Climate Change in Coastal Marine Ecosystems. Annual Review of Marine Science, 5, 371-392. https://doi.org/10.1146/annurev-marine-121211-172411

[25] Côté, I.M., Darling, E.S. and Brown, C.J. (2016) Interactions among Ecosystem Stressors and Their Importance in Conservation. Proceedings of the Royal Society B: Biological Sciences, 283, Article ID: 20152592. https://doi.org/10.1098/rspb.2015.2592

[26] Folt, C.L., Chen, C.Y., Moore, M.V. and Burnaford, J. (1999) Synergism and Antagonism among Multiple Stressors. Limnology and Oceanography, 44, 864-877. https://doi.org/10.4319/lo.1999.44.3_part_2.0864

[27] Griffen, B.D., Belgrad, B.A., Cannizzo, Z.J., Knotts, E.R. and Hancock, E.R. (2016) Rethinking Our Approach to Multiple Stressor Studies in Marine Environments. Marine Ecology Progress Series, 543, 273-281. https://doi.org/10.3354/meps11595

[28] Gunderson, A.R., Armstrong, E.J. and Stillman, J.H. (2016) Multiple Stressors in a Changing World: The Need for an Improved Perspective on Physiological Responses to the Dynamic Marine Environment. Annual Review of Marine Science, 8 , 357-378. https://doi.org/10.1146/annurev-marine-122414-033953

[29] Kroeker, K.J., Kordas, R.L. and Harley, C.D.G. (2017) Embracing Interactions in Ocean Acidification Research: Confronting Multiple Stressor Scenarios and Context 
Dependence. Biology Letters, 13, Article ID: 20160802.

https://doi.org/10.1098/rsbl.2016.0802

[30] Crain, C.M., Kroeker, K. and Halpern, B.S. (2008) Interactive and Cumulative Effects of Multiple Human Stressors in Marine Systems. Ecology Letters, 11, 1304-1315. https://doi.org/10.1111/j.1461-0248.2008.01253.x

[31] Piggott, J.J., Townsend, C.R. and Matthaei, C.D. (2015) Reconceptualizing Synergism and Antagonism among Multiple Stressors. Ecology and Evolution, 5, 1538-1547. https://doi.org/10.1002/ece3.1465

[32] Gattuso, J-P., Magnan, A.K., Bopp, L., Cheung, W.W.L., Duarte, D.W., Hinkel, J., et al. (2018) Ocean Solutions to Address Climate Change and Its Effects on Marine Ecosystems. Frontiers in Marine Science, 5, 337. https://doi.org/10.3389/fmars.2018.00337

[33] Harley, C.D.G., Hughes, A.R., Hultgren, K.M., Miner, B.G., Sorte, C.J.B., Thornber, C.S., et al. (2006) The Impacts of Climate Change in Coastal Marine Systems. Ecology Letters, 9, 228-241. https://doi.org/10.1111/j.1461-0248.2005.00871.x

[34] Halpern, B.S., Frazier, M., Afflerbach, J., O’Hara, C., Katona, S., Lowndes, J.S., et al. (2017) Drivers and Implications of Change in Global Ocean Health Over the Past Five Years. PLoS ONE, 12, e0178267. https://doi.org/10.1371/journal.pone.0178267

[35] Halpern, B.S., Frazier, M., Afflerbach, J., Lowndes, J.S., Micheli, F., O’Hara, C., et al. (2019) Recent Pace of Change in Human Impact on the World's Oceans. Science Reports, 9, Article No. 11609. https://doi.org/10.1038/s41598-019-47201-9

[36] Pörtner, H.-O. (2012) Integrating Climate-Related Stressor Effects on Marine Organisms: Unifying Principles Linking Molecule to Ecosystem-Level Changes. $\mathrm{Ma}$ rine Ecology Progress Series, 470, 273-290. https://doi.org/10.3354/meps10123

[37] Goussen, B., Price, O.R., Rendal, C. and Ashauer, R. (2016) Integrated Presentation of Ecological Risk from Multiple Stressors. Scientific Reports, 6, Article No. 36004. https://doi.org/10.1038/srep36004

[38] Henson, S.A., Beaulieu, C., Ilyina, R., Jasmin, J.F., Long, M., Séférian, R., et al. (2017) Rapid Emergence of Climate Change in Environmental Drivers of Marine Ecosystems. Nature Communications, 8, Article No. 14682. https://doi.org/10.1038/ncomms14682

[39] Rose, J.M., Feng, Y., Di Tullio, G.R., Dunbar, R.B., Hare, C.E., et al. (2009) Synergistic Effects of Iron and Temperature on Antarctic Phytoplankton and Microzooplankton Assemblages. Biogeosciences, 6, 3131-3147.

https://doi.org/10.5194/bg-6-3131-2009

[40] Feng Y., Hare, C.E., Leblanc, K., Rose, J.M., Zhang, Y., Di Tullio, G.R., et al. (2009) Effects of Increased $\mathrm{pCO}_{2}$ and Temperature on the North Atlantic Spring Bloom. I. The Phytoplankton Community and Biogeochemical Response. Marine Ecology Progress Series, 388, 13-25. https://doi.org/10.3354/meps08133

[41] Yang, Y., Hansson, L. and Gattuso, J.-P. (2016) Data Compilation on the Biological Response to Ocean Acidification: An Update. Earth System Science Data, 8, 79-87. https://doi.org/10.5194/essd-8-79-2016

[42] Intergovernmental Panel on Climate Change (2014) Climate Change: Impacts, Adaptation, and Vulnerability, Fifth Assessment Report of the Intergovernmental Panel on Climate Change. Cambridge University Press, Cambridge and New York.

[43] Folke, C., Carpenter, S., Walker, B., Scheffer, M., Elmqvist, T., Gunderson, L. and Holling, C.S. (2004) Regime Shifts, Resilience, and Biodiversity in Ecosystem Management. Annual Review of Ecology, Evolution, and Systematics, 35, 557-581. https://doi.org/10.1146/annurev.ecolsys.35.021103.105711 
[44] Leslie, H.M. (2005) A Synthesis of Marine Conservation Planning Approaches. Conservation Biology, 19, 1701-1713.

https://doi.org/10.1111/j.1523-1739.2005.00268.x

[45] McLeod, K.L. and Leslie, H.M. (2009) Ecosystem-Based Management for the Oceans. Island Press, Washington DC. 